\title{
A criação musical como recurso didático em sala de aula ${ }^{1}$
}

\begin{abstract}
Regina Finck
0 presente trabalho relata alguns dos procedimentos musicais utilizados por cinco meninas de nove a treze anos, em trabalhos de criação musical em grupo, buscando entender e analisar os processos que implicaram na construção do conhecimento musical. Para a realização deste estudo foram analisadas e observadas as atividades de criação musical produzidas por uma turma de Iniciação Musical do Ceart/Udesc. Verificou-se que o grupo realizou, a partir de um desafio lançado pela professora, a estruturação e organização sonora sendo usados para isto elementos musicais e extra-musicais. A organização do objeto sonoro levou a uma ampliação dos fatores musicais, entre eles a capacidade de identificar, relacionar e modificar este objeto. Nesta perspectiva, a abordagem criativa atribuiu uma nova maneira de construir este conhecimento musical.
\end{abstract}

0 trabalho de criação musical vem se constituindo, na última década, em uma das possibilidades de atividade dos educadores musicais frente aos paradigmas do passado. Pesquisadores como Martins (1985), Beyer (1988), Penna (1990), Freire (1992), Oliveira (1992), Santos (1994) sugerem a utilização de novos pressupostos teóricos, já que os antigos não são mais suficientes e, muitas vezes, não têm repercutido, favoravelmente, no meio musical. Além disso, também é necessário reformular os

\footnotetext{
${ }^{1}$ Este artigo relata alguns aspectos da Dissertação e Mestrado "O Fazer Criativo em Música: um estudo sobre o processo da construção do conhecimento a partir da criação musical desenvolvida junto ao Programa de Pós-Graduação em Educação (FACED) da Universidade Federal do Rio Grande do Sul (UFRGS)
} 
pressupostos teóricos, que fundamentam as práticas educativas adotadas pelos profissionais na aula de música.

0 interesse nesta área de estudo surgiu da experiência como professora de Iniciação Musical em que se observou um grande interesse e participação dos alunos na exploração sonora dos instrumentos musicais e na interação através dos sons com os colegas a que se denominou de improvisação e composição coletiva. Essas atividades eram as que despertavam nas crianças, de modo geral, maior motivação. A partir deste enfoque, estruturou-se atividades em sala de aula procurando sempre desenvolver trabalhos de criação musical através da improvisação, da composição e da interpretação, visando a propiciar situações que estimulassem a criatividade dos alunos.

O espaço físico para a realização das aulas foi cedido pelo Departamento de Música do Centro de Artes da Universidade do Estado de Santa Catarina (UDESC). Ao todo foram quinze encontros, com periodicidade semanal e duração de 60 minutos, durante o segundo semestre de 1999.

Assim, as atividades de criação foram pensadas e estruturadas a partir do ideal de fazer com que o aluno de música busque na arte musical um apoio para as suas descobertas sonoras, um canal de expressão do qual aprendese a compartilhar, sugerir, defender e desenhar idéias, obtendo-se acima de tudo, resultados que estimulem suas habilidades individuais. Parte-se do pressuposto que as atividades de criação musical estariam de certo modo, contribuindo para amenizar a problemática, em relação à falta de métodos de educação musical pensados para a realidade brasileira, a reavaliação da postura do profissional que atua em sala e a busca por um 
material pedagógico que focalize a produção dos alunos.

Neste sentido, é essencial que haja um consenso em torno do que os alunos devem saber e ser capazes de fazer em arte, se o que se almeja é uma educação consistente, eficiente e efetiva nesta área. Essa meta depende, por sua vez, de as crianças entenderem o mundo contemporâneo, e encontrarem o seu próprio caminho: "sem artes para ajudar no desenvolvimento da percepção e imaginação dos alunos, as crianças têm grandes chances de se tornarem adultos culturalmente deficientes" (Boletim Arte na Escola, 1995, p.05).

\section{Metodologia}

No processo de iniciação musical, quando se está tentando fazer com que o aluno aprenda a ler $e$ a escrever música, 0 ato criativo representado pela criação deverá estar diretamente ligado a uma experiência prévia com ênfase na prática de execução e improvisação.

Desta maneira, toda tentativa de organizar um conhecimento adquirido na prática dos processos criativos, leva a uma necessária auto-observação: "a compreensão conceitual é praticamente o produto de reflexão sobre o fazer existente" (Beyer, 1995, p.27). Assim, o trabalho de improvisação, composição e interpretação não pode ser executado em sala de aula sem que haja um conhecimento mais aprofundado, uma sistematização desse processo, um estudo de como as crianças constroem essas estruturas musicais, ou seja, os processos cognitivos presentes na aprendizagem musical.

Esse trabalho vem ao encontro de outras propostas de educação musical que compartilham 
o ideal de fazer com que o aluno de música busque na arte musical um apoio para as suas descobertas sonoras, um canal de expressão através do qual aprende-se a compartilhar, sugerir, defender e desenhar idéias, obtendo-se acima de tudo, resultados que estimulam suas habilidades individuais.

Assim, no momento em que se sugeriu a estruturação de uma série de experimentos, através da criação musical, realizados com 05 meninas de idades diferentes, estava-se tentando compreender qual o conhecimento e quais as habilidades que essas alunas tinham sobre música, a natureza desse conhecimento musical e os mecanismos que entram em jogo para a sua aquisição, a evolução e o desenvolvimento do pensamento desta linguagem específica.

\section{Abordagens cognitivas em música}

Com a nova Lei de Diretrizes e Bases da Educação (LDB, Lei 9394) sancionada em 1996, que prevê a obrigatoriedade do ensino de artes, um maior número de escolas particulares e públicas estão adotando esta disciplina em seus currículos. Além da LDB prever o ensino de artes, a inserção da disciplina de educação musical nas escolas deve-deve-se, também, ao reconhecimento da música como linguagem e área de conhecimento. Neste sentido, "conhecer e praticar as disciplinas artísticas é fundamental para o desenvolvimento saudável do espírito e da mente das crianças. É por isso que em qualquer civilização inclusive a nossa as artes são inseparáveis do real significado do termo “educação'” (Boletim Arte na Escola, 1995, p. 04).

Ao mesmo tempo em que se procurou estratégias para desenvolver a criatividade 
musical através da adoção de improvisação e de composições musicais, sentiu-se a necessidade de fundamentar a prática pedagógica na gênese do conhecimento musical, temática ainda pouco estudada no Brasil. Conhecendo as etapas e processos que a criança percorre na construção do pensamento musical (Beyer, 1995, 1996), a ação pedagógica do professor poderá ser mais significativa e efetiva, apontando para alternativas metodológicas no ensino música e, mais especificamente, na criação musical, atividade que se mostra especialmente propícia para esse campo de estudo, por permitir a análise das hipóteses que a criança elabora ao construir o seu discurso musical.

No entanto, diferentemente do amparo pedagógico encontrado em outras áreas de conhecimento, o professor de música carece de pesquisas na área da cognição musical. Este professor, que se limitava a trabalhar em escolas livres e ou conservatórios de música, subitamente depara-se com uma realidade bastante distinta encontrada na sala da aula. Considera-se, por exemplo, o grande número de alunos nas turmas, em escolas públicas, que é um dos aspectos que costumeiramente dificultam 0 trabalho de professores em sala de aula. Além disso, é necessário considerar os fatores sociais, culturais e econômicos desses alunos e, ainda, a dinâmica do processo de ensino-aprendizagem que permeiam a educação musical.

Naturalmente, essa linguagem está vinculada às discussões relativas ao ensino de artes de modo geral e, conseqüentemente, as demais disciplinas que fazem parte de um currículo escolar. Atualmente, esses debates tentam definir qual o conhecimento e quais as habilidades que os alunos devem ter nessas áreas a fim de desenvolverem seu potencial pessoal, tornarem-se trabalhadores produtivos e 
competitivos em uma economia global e assumirem seus lugares como cidadãos adultos.

Desta maneira, o sucesso educacional, dos alunos, depende da criação de uma sociedade que seja ao mesmo tempo culta e imaginativa, competente e criativa. Goleman (1992, p.75), reforça a necessidade do ensino de artes afirmando que "a exposição a um leque maior de habilidades do que o oferecido pela escola convencional não apenas estimula os talentos naturais das crianças como as prepara de um modo melhor e mais abrangente para a vida".

Neste sentido, há a necessidade de aproximar a área da música com estudos já comprovados pela educação de uma forma mais ampla. Sabe-se que atividades musicais criativas necessitam acima de tudo de uma abordagem cognitiva, pois conhecendo os processos que a criança percorre na construção do pensamento musical (Beyer,1988,1993,1994,1995,1996) a prática pedagógica do professor de música poderia oferecer aos seus educandos muito mais do que uma fonte de prazer, mas também, uma possibilidade de construção e entendimento do fazer música (prática do discurso musical) e, principalmente, a compreensão do seu significado, das imagens mentais desses sons. Para Beyer, a formação de um conceito implica numa vivência anterior, em nível prático, ou seja, uma construção de esquemas sensórios-motores, simbólicos e intuitivos.

0 desenvolvimento do pensamento musical, neste estudo, parte de uma abordagem cognitiva ${ }^{2}$. Para uma melhor compreensão do que seria essa abordagem cognitiva em música optouse pelas teorias elaboradas por duas pesquisadoras: Beyer (1988) e Serafine (1983).

\footnotetext{
${ }^{2}$ A cognição amplamente estudada e descrita por Piaget (1978, 1990), partiu da premissa básica em desvendar como se adquire o conhecimento. 
Para a construção da teoria cognitivamusical, Beyer parte da necessidade da abordagem cognitiva tendo em vista a busca dos requisitos básicos para que exista uma teoria musical. Destaca, portanto, a compreensão da prática musical, ou seja, como ela ocorre, considerando que esta teoria não pode aplicar-se apenas a elementos isolados, mas sim, necessita de um todo coerente, buscando uma aproximação da linguagem musical e o estabelecimento dos paralelos entre o conhecimento científico e o conhecimento artístico.

A música como cognição, é entendida por Serafine como uma atividade de pensar com sons, e, por conseguinte, o termo mais apropriado seria o pensamento musical como sendo: "uma atividade humana de conhecimento aural (sonoro), que resulta da formulação de trabalhos de arte expressando finitos e organizados conjuntos de sucessão temporais descritos no som" (Serafine apud, Moreno, 1995, p.122).

A teoria proposta por Serafine parte da concepção de que a música é um fenômeno cultural que nasce nos grupos de pessoas que formam as chamadas comunidades musicais, e que compartilham pensamentos comuns sobre como a música é composta, interpretada e ouvida. Para ela, nenhuma cultura existe sem música. Assim, as pessoas que formam este tipo de cultura e que se dedicam à música, ocupam-se numa grande variedade de comportamentos tais como: compor, interpretar e escutar. Essas condutas são uma clara manifestação do conhecimento sobre a música e do pensamento musical. Ignorando-se essas condutas (compor, escutar e interpretar) os produtos musicais darse-iam casualmente, submergidos pelo emprego técnico e repetitivo do conhecimento musical. 
Swanwick (1988), destaca o valor das atividades de composição musical no processo educativo, conjuntamente com atividades de execução e apreciação musical. 0 autor pesquisou os estágios de desenvolvimento da composição musical, da infância à idade adulta, estabelecendo critérios para a avaliação de produtos musicais em composição, execução e apreciação.

Propostas neste sentido já vêm sendo estudadas e focalizam a atividade de criação em música aliada a atividades de execução e apreciação, como sendo uma das alternativas para a obtenção do desenvolvimento musical equilibrado.

\section{0 fazer criativo em música}

De forma geral, entende-se por educação musical, além dos múltiplos sentidos que o termo abarca, toda a ação exercida por um indivíduo sobre outro com um objetivo musical, implícito ou não. Quando um educador promove uma situação de ensino musical, o conhecimento produzido é resultado de um processo dinâmico, ou seja, se por um lado, o aluno interage com seus pares, ao mesmo tempo em que estabelece trocas enriquecedoras com a mediação do professor, por outro, o próprio educador amplia seus conhecimentos com a contribuição das experiências dos alunos.

No caso específico da criação musical, o ato criativo é um fator decisivo na concretização de obras. Essas obras manifestam-se como unidades virtuais, já que remetem a coisas que não têm existência real, mas sim, idealizadas e imaginadas no subjetivo. Pode-se dizer que a obra de arte, mais especificamente a obra musical, não expressa apenas determinados sentimentos e 
emoções, mas é através dessa configuração particular do subjetivo, no criar musicalmente, que há a motivação para construir essas idéias e concretizá-las.

Este procedimento de reconstrução sonora fundamenta-se nos mecanismos da memória e no manejo consciente das diversas possibilidades do objeto sonoro. Um correto emprego destes fatores permitirá um armazenamento maior de dados, como também a possibilidade de gerar outros novos, mediante processos de associação e transferências.

$\mathrm{Na}$ educação musical, o ato criador está diretamente ligado aos processos de improvisação, composição e interpretação. Por serem essas atividades desenvolvidas em grupos, certamente envolverá diferentes níveis de desenvolvimento e habilidades particulares das crianças, da maneira de sentir, pensar, agir e reagir em situações concretas, no caso específico, no instrumento musical e, conseqüentemente, na produção e criação musical. No entanto, esta produção de forma alguma deve ser interpretada como uma falta de 'organização' e de 'definição' de parâmetros que sejam norteadores de criação da obra musical. Para a concretização de uma obra musical pode-se considerar o conhecimento de três fatores fundamentais: o material sonoro; os problemas do tempo - dimensão esta na qual vão desencadear-se os acontecimentos sonoros; e as possibilidades de seleção e combinação dos sons em função de uma finalidade desejada.

Assim, com relação ao desenvolvimento do momento de criação buscou-se apoio em Cauduro (1993), Barrett (1996 e 1999), Kraus (1975), Schafer (1991), Pontious (1986), Paynter (1972), Curriculum and Standards Framework (1995), Burnard (1998). Estes autores permitem um embasamento teórico para orientar uma 
proposta de criação musical, em sala de aula, fundamentada em quatro elementos básicos:

a) no resgate sonoro (exploração sonora, pesquisa dos sons, escolha dos instrumentos e seus respectivos timbres, improvisação);

b) na elaboração sonora (definição de padrões rítmicos e melódicos a serem empregados, desejo ou, intenção do autor);

c) na estruturação e organização do objeto sonoro (definição de motivos, frases, variações, formas, escrita formal ou informal);

d) na interpretação da composição a partir dos elementos citados acima.

Evidentemente organizar um processo de criação musical é naturalmente difícil, pois envolve uma série de elementos. No entanto, desenvolvê-lo constitui-se num desafio para os educadores musicais que estimulam a criatividade natural de seus educandos e aprendem a desenvolvê-la, a fim de responder às necessidades de uma sociedade complexa e competitiva. E como estudo e competência se complementam, o prazer de aprender torna-se real, tangível e transformador.

É neste sentido que se procurou construir e sistematizar uma série de atividades musicais que, com enfoque criterioso, permitam desenvolver experiências criativas interligadas aos elementos constitutivos da música. Dessa maneira, acredita-se poder orientar o desenvolvimento de atividades musicais criativas aos educandos fora dos limites restritivos de 
certos métodos de educação musical, importados de outras realidades sócio-culturais. Esses métodos provindos de outras culturas e produzidos em outras épocas, atualmente encontram-se defasados e até mesmo superados em virtude das rápidas transformações sociais e dos novos meios de transmissão de conhecimentos que permeiam as escolas.

Acredita-se que os objetivos em se desenvolver e sistematizar possibilidades de criação musical deveriam ser a primeira instância das potencialidades criadoras dos alunos possibilitando assim, uma maior compreensão estética das manifestações do espírito humano.

0 trabalho de criação musical desenvolvido com o grupo de alunas participantes da pesquisa constituiu-se em atividades que partiram de uma orientação prévia da professora determinando as diretrizes que permeariam as atividades do dia.

\section{As estratégias}

O trabalho de criação musical do grupo se orientou pelas atividades de criação previstas nos currículos Manhattanville (Thomas, 1970), Wisconsin (Pontious 1986), Curriculum and Standards Framework (Vitória/Austrália, 1995), bem como as sugestões indicadas pelos pesquisadores Saitta (1978), Leduc (1975), Schafer (1991), Paynter (1975), e Moore (1990) e foram estruturadas e planejadas pela pesquisadora para orientar as criações do grupo de meninas e, principalmente, para que se chegasse a uma linha geral de ação e fossem estabelecidos os processos de criação musical. Dentre as principais estratégias utilizadas para o trabalho de criação musical pode-se citar: 
- Promover curtas improvisações individuais dentro de formas maiores executadas pelo grupo;

- Recriar uma canção conhecida;

- Imaginar o movimento sonoro produzido pela fonte de som e desenhá-lo e ou diagramá-lo no papel;

- Organizar uma audição de gravações de música que incorpore sons que os alunos consigam reconhecer;

- Estimular os alunos a imaginarem e descreverem uma composição com fontes sonoras imediatamente disponíveis, como suas vozes, por exemplo;

- Desafiar os alunos para criarem arranjos musicais;

- Incluir diversas experiências de audição contemporânea em sala;

- Ampliar ou recriar gráficos sonoros;

- Sonorizar imagens - livros sem textos;

- Criar seqüências de sons explorando diferenças de dinâmica, duração, intensidade e altura;

- Aumentar, recompor ou recriar e interpretar composições de outros grupos;

- Organizar ritmos dentro de um período de tempo estipulado previamente;

- Criar acompanhamento instrumental ou corporal para melodias.

\section{Estratégias utilizadas para o desenvolvimento de atividades criativas}


Normalmente, depois de uma seleção feita dos instrumentos a serem utilizados na atividade, eram definidos os timbres. 0 segundo passo consistia no estabelecimento do padrão rítmico ou melódico a ser utilizado na composição bem como a seqüência dos instrumentos. Feita a experimentação, a seleção e a organização do objeto sonoro partia-se para a terceira etapa que consistia na representação gráfica, através da escrita não formal em música. A Figura 01, a seguir, pode exemplificar o trabalho realizado a partir de uma recriação da "Lâmina B" (Saitta, 1978). Trata-se de uma partitura de música com escrita não formal.

A partir do modelo (Figura 01) o grupo deveria ampliar a composição e representar graficamente 0 novo trecho musical (ver Figura 02).

\section{A discussão dos dados}

Observou-se que, em alguns encontros, o grupo já chegava com um esboço do que queria criar. É o caso, por exemplo, da composição intitulada "Batucada". As meninas estabeleceram, nesse encontro, que queriam criar um "sambão" e, assim, coube a professora ajudá-las a sistematizar os elementos musicais.

É interessante observar que nas primeiras composições do grupo não houve registro gráfico. Mesmo assim, numa composição musical que previa uma forma específica, A/B/A, por exemplo, as meninas conseguiram, com pouca variação melódica e rítmica, manter a estrutura sonora pensada originalmente, no momento da composição.

Depois destas atividades podemos considerar alguns pontos para reflexão: 


\section{0 trabalho em equipe:}

a) o diálogo: a primeira parte da análise feita pelas meninas quando estavam estabelecendo a estrutura da peça. Elas sempre estavam dialogando, para chegar a um senso comum. Enquanto elaboravam o discurso musical, surgiam, naturalmente, os motivos rítmicos e melódicos. 0 grupo experimentava e selecionava esses motivos e, a estrutura final da peça ia surgindo. Nas atividades criativas destaca-se como fundamental o trabalho em grupo pois este constitui-se em um meio natural de atividade intelectual e a cooperação 0 instrumento necessário à formação do pensamento racional. A técnica de "trabalho por equipes" constitui-se numa fonte de iniciativa, já que há correlação entre a personalidade e as relações sociais de cooperação a equipe desenvolve a independência intelectual de seus membros (Piaget, 1986, p. 06).

b) a liderança: é importante destacar a liderança nestes momentos de seleção e exclusão dos elementos musicais experimentados. Geralmente, a função de líder do grupo dependia muito do tipo de música que estava sendo criada, ou seja, se a ênfase estava na melodia ou no ritmo. No momento em que passou a se cobrar a representação gráfica das peças a liderança do grupo também era alternada. Nem sempre quem dava as idéias aceitas pelo grupo e incorporadas às peças, era também, aquela que assumia a liderança na representação gráfica. 


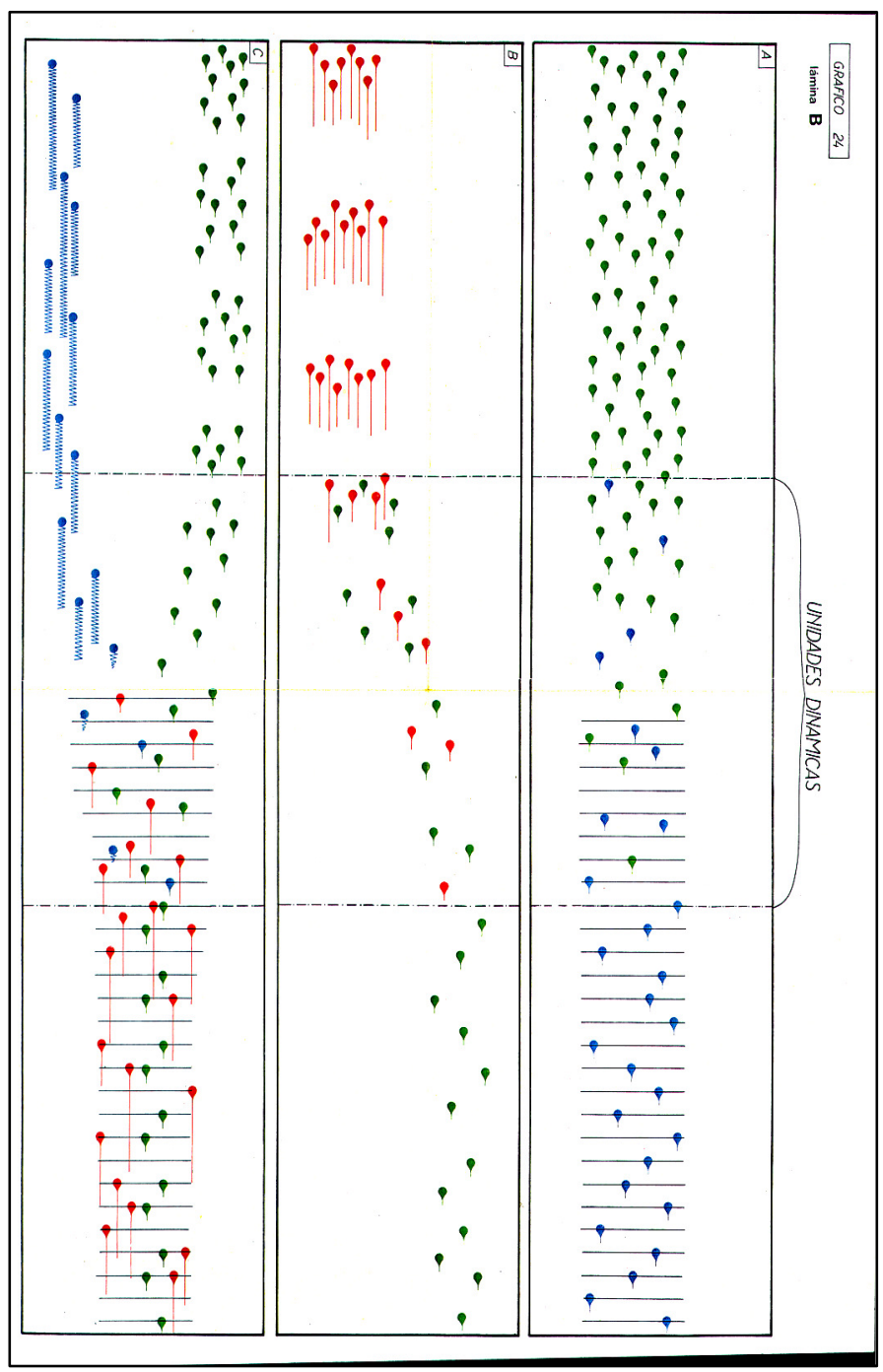

Figura 01 Partitura “Gráfico 24 - Lâmina B” Saitta (1978) 


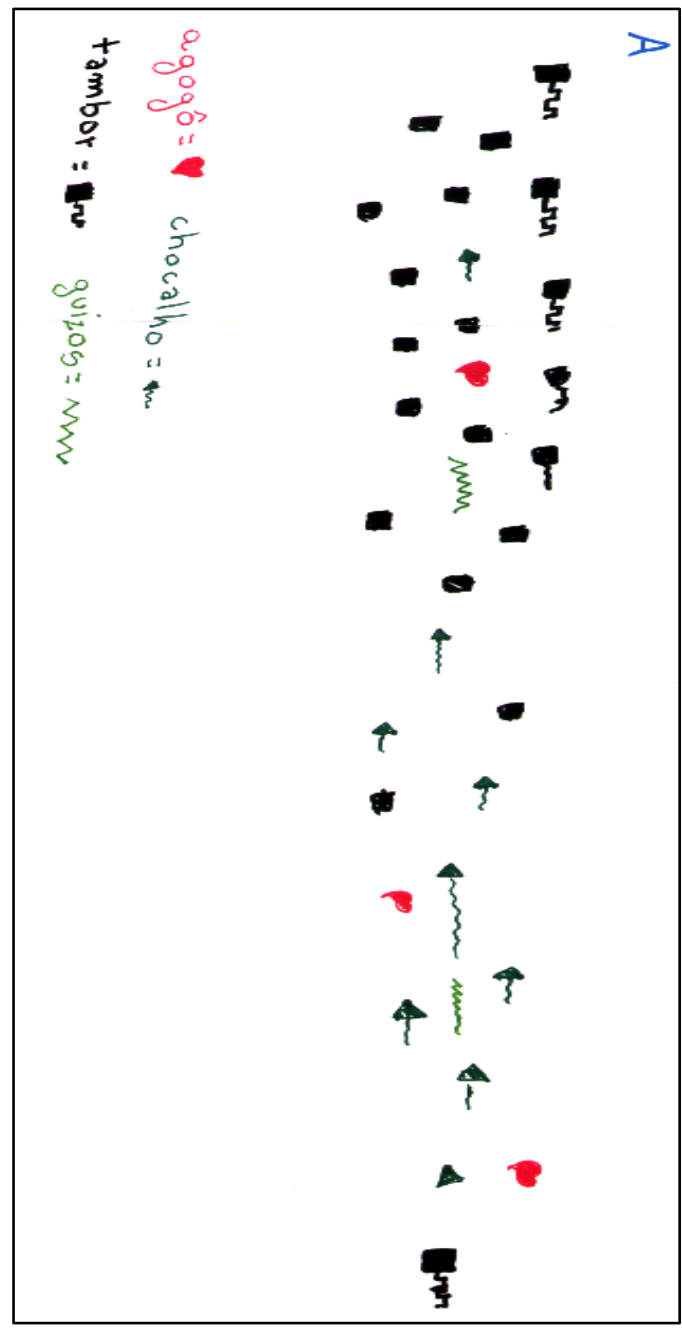

Figura 02 Partitura "Re-criação do Gráfico 23 - Forma A" 


\section{A Representação Gráfica:}

Outro ponto a destacar refere-se à representação gráfica. Uma das atividades realizadas constituiu-se em dividir o grupo. Cada grupo, separadamente, elaborou e representou graficamente uma composição. Esta composição também foi gravada. O próximo passo da atividade foi dar essa "partitura" para o outro grupo tocar. Observou-se que a nova interpretação da representação gráfica dada pelo grupo foi contestada, principalmente com relação ao parâmetro de duração do som. No entanto, alguns elementos da obra foram aprovados pelas autoras (altura grave/médio/agudo). Com essa atividade verificou-se, com o grupo, a necessidade de uma representação clara da obra. 0 grupo salientou a necessidade de estabelecer legendas para um resultado mais aproximado do idealizado pelo autor.

A Figura 04 a seguir, evidencia como o grupo representou os aspectos melódicos e rítmicos. Também é possível verificar a utilização das cores para representar os timbres.

Nessa representação gráfica, nota-se que o grupo buscou representar os parâmetros do som como altura, timbre e duração.

\section{O Modelo pré-estabelecido:}

Com relação à atividade de criação a partir de um modelo pré-estabelecido, o grupo de meninas ouviu uma obra do compositor contemporâneo Stockhausen. A partir dessa apreciação sonora, elas deveriam criar aos moldes da peça “Liaison" (CD Aus den sieben Tagen 1988) uma composição sem o estabelecimento de padrões rítmicos e melódicos. 0 grupo sentiu 


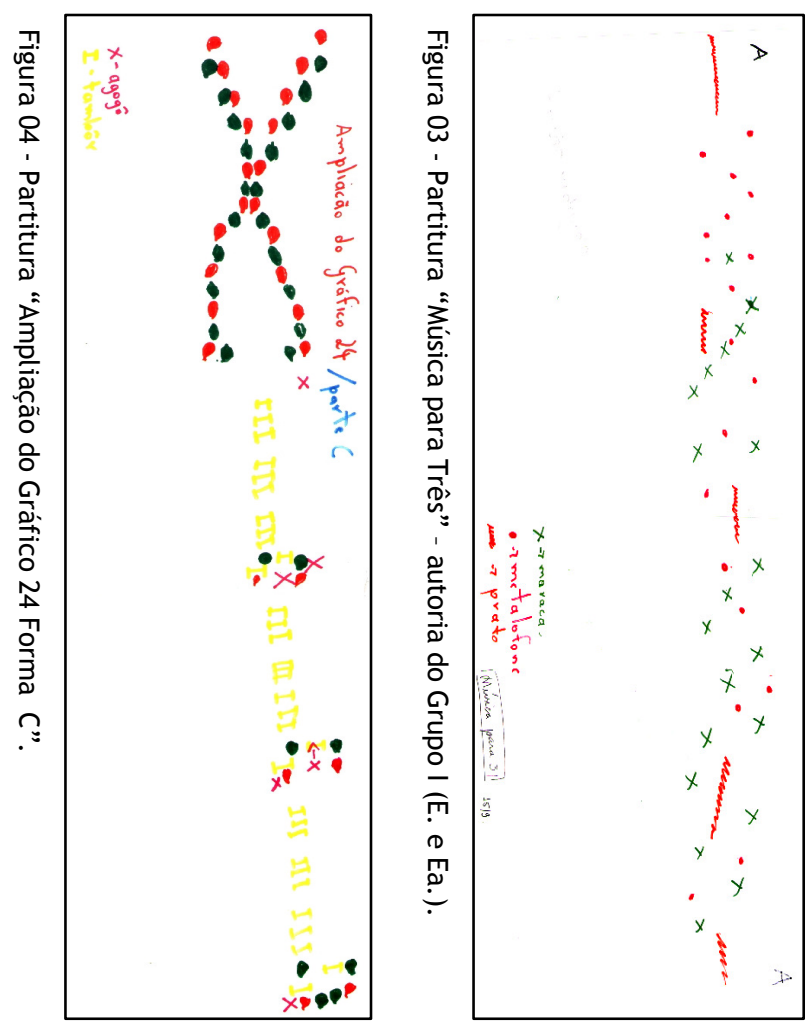


dificuldades em criar uma peça desta natureza, inclusive, durante a apreciação ouviu-se comentários tais como: isso é música? Apesar das dificuldades iniciais em criar uma peça com base na música contemporânea o grupo estabeleceu como princípio básico os padrões sonoros semelhantes a um diálogo. Nesta peça a base utilizada pelo grupo foi o timbre. A composição chamou-se: 'O debate'. (ver Figura 5).

O trabalho em sala de aula colocou em evidência a importância de se trabalhar com repertório mais contemporâneo e um novo acervo de partituras. Em contato com o grupo, a pesquisadora percebeu a necessidade em se trabalhar com novas formas de escrituras notacionais. Assim, essas experiências, foram desenvolvidas com livros de imagens, poemas ou textos narrativos e gráficos de escrita analógica e, constituiu-se como uma forma reveladora de caminhos não imaginados anteriormente. Nesta perspectiva, a importância deste estudo consistiu em mostrar que a experiência, o fazer musical inventivo dos alunos é uma etapa importante na produção de objetos sonoros e do conhecimento musical e, deste modo, constitui-se fundamental na continuidade do aspecto motivacional para as aulas de música. 


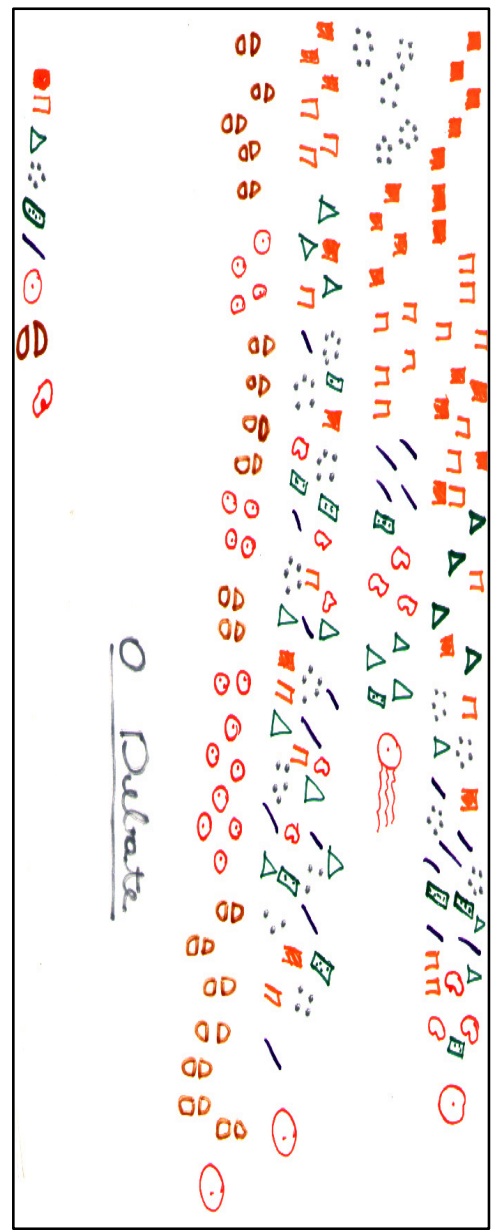

Figura 05 - Partitura “O Debate” 


\section{Referenciais bibliográficos}

BARRETT, M.S. Accessing the Chil's View. Lauceston: Austrália:, 1999.

.Children's aesthic desicion-making. Michigan: ISME, 1996.

BEYER, E. A construção de conceitos musicais no indivíduo: Perspectivas para a Educação Musical. Em Pauta. Porto Alegre Ano VI/VII, $n^{\circ} 9 / 10$, p. 2231, dez. 94/95.

A abordagem Cognitiva em Música. Uma crítica ao ensino de música a partir da teoria de Piaget. Dissertação (Mestrado em Educação) Faculdade de Educação, UFRGS, Porto Alegre, 1988.

A construção do conhecimento musical na primeira infância. Em Pauta, ano V, n. ${ }^{\circ} 8$, p. 4858, dez. 1993.

A reprodução e a produção musical em crianças: uma perspectiva cognitiva. In: OLIVEIRA, A. et al. Música: pesquisa e conhecimento. Porto Alegre: NEA/CPG Música, UFGRS, 1996, p. 69-97.

BOLETIM ARTE NA ESCOLA. Reforma Educacional nos Estados Unidos As normas e as artes, n. ${ }^{\circ} 10$. Abril, Porto Alegre. 1995

BURNARD, P. Children's musical creativity: Pretoria, África do Sul: UNISA, 1998.

CAUDURO, V.R.P. Estimulando a criatividade Musical na sala de aula. Porto Alegre: UFRGS, 1993.

CURRICULUM AND STANDARDS FRAMEWORK The Arts. Victória, Austrália: Board of Studies, 1995.

FREIRE, V. L. B. Música e Sociedade. Uma perspectiva histórica e uma reflexão aplicada ao ensino superior de música. ABEM, Série Teses 1. Rio de Janeiro: UFRJ, 1992. 
GOLEMAN, D. et all. O Espírito Criativo. São Paulo: Cultrix, 1992.

KRAUS, E. Kreatives Spiel mit Klängen.1975.

LEDUC, A. Percustra. v. $1^{\mathrm{A}}, 2^{\mathrm{A}}$. Paris: 1975 .

MARTINS, R. Educação Musical: conceitos e preconceitos. Instituto Nacional de Música. Coordenadoria. Rio de Janeiro: Funarte, 1985.

MOORE, J. Strategies for Fostering Creative Thinking. Music Educators Journal (MEJ), maio, 1990.

MORENO, J. L. La teoria Cognitiva de Serafine. Madrid: Riccordi, 1995.

OLIVEIRA, A. de J. 0 paradoxo da criação na Educação Paradoxal. In: Revista da Escola de Música. Art 19. Agosto, UFBA. 1992.

PAYNTER, J. Oir, Aqui y Ahora. Buenos Aires: Ricordi, 1972.

PAYNTER, J. \& ASTON, P. (1975). Sound and Silence. London, Cambridge University Press.

PENNA, M. Reavaliações e Buscas em Musicalização. Edições, Loyola: São Paulo, 1990.

PIAGET, J. et.al. Fazer e Compreender. São Paulo: Melhoramentos/EDUSP, 1978. - O trabalho por equipes na escola. Revista de Educação, São Paulo, Diretoria do Ensino do Estado de São Paulo,1986.

A formação do símbolo na criança. Rio de Janeiro: LTC, 1990.

PONTIOUS, M.A Guide Curriculum planning In Music Education.Madison:Wisconsin, 1986.

SAITTA, C. Creacion e Iniciación Musical. Buenos Aires: Ricordi, 1978

SANTOS, R. M. S. A natureza da aprendizagem musical e suas implicações curriculares - análise comparativa de quatro métodos, In: Fundamentos 
de Educação Musical. Série Fundamentos $n^{\circ} 02$. Porto Alegre: UFRGS,1994.

SERAFINE. M.L. Cognition in Music. Cognition. New York:, 1983.

SWANWICK, K. Music mind and education. London Routledge: 1988.

SHAFER, M. O Ouvido pensante. São Paulo: UNESP, 1991.

THOMAS, R. B. Manhattanville music curriculum program. New York: Média Materials. Inc, 1970. 